\title{
Sexual Dysfunction After Conventional and Endovascular AAA Repair: Results of the DREAM Trial
}

\author{
Monique Prinssen, MD1; Erik Buskens, MD2; Rudolf P. Tutein Nolthenius, MD³; \\ Steven M.M. van Sterkenburg, MD; Joep A.W. Teijink, MD5; and \\ Jan D. Blankensteijn, MD ${ }^{6}$ on behalf of the DREAM Trial Participants
}

1Division of Vascular Surgery, Department of Surgery; and 2Julius Center for Health Sciences and Primary Care, University Medical Center Utrecht, The Netherlands. 3Department of Surgery, Albert Schweitzer Hospital, Dordrecht, The Netherlands. "Department of Surgery, Rijnstate Hospital, Arnhem, The Netherlands. ${ }^{5}$ Department of Surgery, Atrium Medical Center, Heerlen, The Netherlands. ${ }^{6}$ Department of Vascular Surgery, Radboud University Nijmegen Medical Center, Nijmegen, The Netherlands.

Purpose: To assess sexual function in the first postoperative year after elective endovascular aneurysm repair (EVAR) and open repair (OR) of abdominal aortic aneurysm (AAA). Methods: In the Dutch Randomized Endovascular Aneurysm Management (DREAM) trial, 153 patients ( 141 men; mean age 71 years, range 53-85) were randomly allocated to EVAR $(n=77)$ or OR $(n=76)$. Sexual functioning was evaluated preoperatively and at 5 times in the first postoperative year $(3,6,13,26$, and 52 weeks) using a questionnaire derived from the Medical Outcomes Study. The proportions of patients reporting sexual dysfunction for any of 5 aspects (interest, pleasure, engagement, orgasm, and erection) and any increase in the magnitude of dysfunction were compared between EVAR and OR.

Results: Preoperatively, the proportion of patients reporting sexual dysfunction in at least 1 aspect was $66 \%$ for the OR group and $74 \%$ in the EVAR group ( $p=N S$ ). Surgery had a clear impact on sexual dysfunction. The proportion of patients reporting sexual dysfunction on at least 1 aspect increased to $79 \%$ in the OR group and $82 \%$ in the EVAR group. The magnitude of sexual dysfunction increased in both groups on all 5 aspects at 3 weeks postoperatively, but this was more pronounced in the OR group (interest: OR $p=0.038$ vs. EVAR $p=0.071$; pleasure: OR $p=0.009$ vs. EVAR $p=0.065$; engagement: $O R p=0.006$ vs. EVAR $p=0.054$; orgasm OR $p=0.023$ vs. EVAR $p=0.112$, and erection: OR $p=0.046$ vs. EVAR $p=0.030$ ). At 6 weeks, the OR group still reported a significant increase in 3 aspects (pleasure $p=0.031$, engagement $p=0.010$, and orgasm $p=0.003)$, whereas the EVAR group no longer showed a significant difference. From 3 months on, both groups had returned to baseline.

Conclusions: EVAR and open elective AAA repair both have an impact on sexual function in the early postoperative period. After EVAR, recovery to preoperative levels is faster than after open repair, but at 3 months, sexual dysfunction levels are similar in both groups.

J Endovasc Ther 2004;11:613-620

Key words: abdominal aortic aneurysm, endovascular repair, surgical repair, comparative study, sexual dysfunction, questionnaire, outcome analysis, randomized trial 
Open abdominal aortic aneurysm (AAA) repair has been associated with impairment of sexual functioning. Sexual dysfunction after open repair (OR) of AAA is often attributed to autonomic nerve injury and changes in pelvic blood supply. As endovascular aneurysm repair (EVAR) does not require dissection in the area of the iliac bifurcation, it is expected not to affect sexual functioning. However, little is known about this subject. There is clinical evidence that sexual problems have a mixed etiology, with physical, medical, social, and psychological components. So, it is not unlikely that other factors may be responsible for the sexual impairment after OR also. ${ }^{1,2}$ Only a few studies have focused on sexual dysfunction after AAA repair, most in conjunction with conventional surgery. ${ }^{3-5}$ The aim of our study was to assess sexual functioning in the first postoperative year after elective EVAR and OR in a randomized study.

\section{METHODS}

\section{Study Design and Patient Samples}

In the Dutch Randomized Endovascular Aneurysm Management (DREAM) trial, 153 patients (141 men; mean age 71 years, range 53-85) suitable for both treatments were randomly allocated to EVAR $(n=77)$ or OR $(n=76)$ between November 1999 and August 2002. There was 1 crossover from OR to EVAR, but the analysis was based on intention to treat. The study design has been described in detail elsewhere. ${ }^{6}$ The Institutional Review Boards of all participating hospitals (Appendix) approved the study, and informed consent was obtained from each patient.

Sexual functioning was assessed on a scale adapted from the Medical Outcomes Study (MOS), ${ }^{7}$ which consists of 5 questions concerning sexual functioning (Table 1). The questionnaire was sent to all patients preop- eratively and at 5 time points in the first postoperative year $(3,6,13,26$, and 52 weeks). If the questionnaire was not filled out completely, questions were completed with a telephone call. For analysis purposes, a patient was considered to report sexual dysfunction for each of the items if any of the following answers were given: completely agree, partly agree, and partly disagree.

\section{Statistical Analysis}

Baseline characteristics (age, gender, SVS/ AAVS [Society for Vascular Surgery/American Association for Vascular Surgery] risk score, ${ }^{8}$ and medication) of patients in both trial arms were compared with the Student $t$ and chisquare tests. The proportion of patients reporting sexual dysfunction on at least 1 of the 5 aspects and the proportion for each individual aspect of sexual functioning were calculated and compared between the EVAR and OR groups using the Fisher's exact test. Changes in the magnitude of sexual dysfunction over time versus the preoperative value were analyzed with the Wilcoxon signed rank test. Analyses were performed using SPSS version 11.0 (SPSS Inc., Chicago, IL, USA). $\mathrm{P}<0.05$ was considered significant.

\section{RESULTS}

There were no differences in baseline characteristics between the EVAR and OR groups (Table 2). Both pre and postoperatively, there were no significant differences between the trial arms in the number of patients using any $\beta$-blockers, calcium-channel blockers, digoxin, or diuretics. Preoperatively, $64 \%$ of the patients in the OR group used one or more of these medications compared to $51 \%$ in the EVAR group.

In the OR group, 47 patients received an aorto-aortic tube graft and 30 a bifurcated

This study was funded by the Dutch Health Insurance Council (OG68).

Presented at the International Congress XVII on Endovascular Interventions, Scottsdale, Arizona, USA, February 8-12, 2004.

Address for correspondence and reprints: Jan D. Blankensteijn, MD, Chief Department of Vascular Surgery, Surgery 410, Radboud University Nijmegen Medical Center, PO Box 9101, 6500 HB Nijmegen, The Netherlands. Fax: 31-24-3540501; E-mail: j.blankensteijn@chir.umcn.nl 
TABLE 1

Medical Outcomes Study Questionnaire on Sexual Functioning

\begin{tabular}{|c|c|c|c|c|}
\hline Do you agree or disagree with the following statements? & $\begin{array}{c}\text { Completely } \\
\text { agree }\end{array}$ & $\begin{array}{l}\text { Partly } \\
\text { agree }\end{array}$ & $\begin{array}{l}\text { Partly } \\
\text { disagree }\end{array}$ & $\begin{array}{c}\text { Completely } \\
\text { disagree }\end{array}$ \\
\hline a. I'm not interested in sex & $\square$ & $\square$ & $\square$ & $\square$ \\
\hline b. I have difficulties in relaxing and enjoying sex & $\square$ & $\square$ & $\square$ & $\square$ \\
\hline c. I have difficulties in becoming sexually aroused & $\square$ & $\square$ & $\square$ & $\square$ \\
\hline d. I have difficulties in having an orgasm & $\square$ & $\square$ & $\square$ & $\square$ \\
\hline e. I have difficulties in getting and/or keeping an erection (for men only). & $\square$ & $\square$ & $\square$ & $\square$ \\
\hline
\end{tabular}

graft; in the EVAR group, all endografts were bifurcated except 1 tube graft. Internal iliac artery patency after surgery was unchanged in $72 / 77$ (94\%) patients assigned to the OR group and $61 / 76(80 \%)$ patients assigned to the EVAR group $(p=0.017)$. One or bilateral patent internal iliac arteries were lost in 5 OR and in 14 EVAR patients; in addition, a single internal iliac artery (with preexistent contralateral occlusion) was sacrificed in 1 EVAR patient. Postoperatively, impaired sexual functioning was reported spontaneously at office visits by 2 patients in the OR group and by 1 in the EVAR patients.

The preoperative questionnaire response rate was $69 \%$ in the OR group and $87 \%$ in the EVAR group $(p=0.007)$. The postoperative response rates for OR and EVAR were $61 \%$ versus $66 \%(p=0.542)$ at 3 weeks, $61 \%$ versus $66 \%(p=0.542)$ at 6 weeks, $71 \%$ versus $70 \%$ $(p=0.818)$ at 13 weeks, $69 \%$ versus $68 \%$ $(p=0.956)$ at 26 weeks, and $69 \%$ versus $67 \%$ $(p=0.819)$ at 52 weeks.

The preoperatively reported sexual dysfunction rate (Table 3 ) was high in both groups; for the individual items, the proportions varied between $48 \%$ and $56 \%$ in the OR group and $53 \%$ and $60 \%$ in the EVAR group. Preoperatively, the percentage of patients reporting sexual dysfunction on any of the 5 aspects was $66 \%$ in OR group and $74 \%$ in the EVAR group $(p=N S)$. There was no statistically significant difference in the proportion of patients reporting sexual dysfunction between the 2 groups for any of the 5 aspects at any time point or for sexual dysfunction in at least 1 aspect.

Nevertheless, surgery did have an impact on sexual functioning in both groups (Figure). Three weeks after surgery, the reported rate of sexual dysfunction on any of the 5 aspects increased to $79 \%$ in the OR group and $82 \%$ in the EVAR group. Looking at the reported changes in magnitude of sexual dysfunction at 3 weeks compared to preoperative values (Table 4), the OR group reported a significant increase on all 5 aspects (interest $p=0.038$, pleasure $p=0.009$, engagement $p=0.006$, orgasm $p=0.023$, and erection $p=0.046$ ). In the EVAR group, there was an increased magnitude of sexual dysfunction on all aspects also, but only 1 (erection $p=0.030$ ) reached statistical significance (other aspects not significantly increased: interest $p=0.071$, pleasure $p=0.065$, engagement $p=0.054$, and orgasm $p=0.112$ ). Six weeks postoperatively, the OR group still reported a significant increase in the magnitude of sexual dysfunction on 3 aspects (pleasure $p=0.031$, engagement $p=0.010$, and orgasm $p=0.003$; other aspects not significantly increased: interest $p=0.168$ and erection $p=0.111$ ). The EVAR group showed no significant difference at 6 weeks (interest $p=0.674$, pleasure $p=0.855$, engagement $p=0.773$, orgasm $p=0.768$, and erection $p=0.519$ ). From 3 months on, both groups had returned to their preoperative level of sexual functioning.

\section{DISCUSSION}

Few reports addressing the impact of OR and EVAR on sexual functioning have been published. In the available literature, most studies are retrospective in nature and focus primarily on impotence and erectile dysfunction after conventional open AAA repair.4,5,9 To our knowledge, no randomized study has compared sexual function after OR and EVAR until now. 
TABLE 2

Baseline Characteristics According to the SVS/AAVS Risk Factor

\begin{tabular}{|c|c|c|}
\hline & OR $(n=76)$ & $\operatorname{EVAR}(n=77)$ \\
\hline Men & $69(91 \%)$ & $72(93 \%)$ \\
\hline Median age, y (range) & $70(53-85)$ & $70(55-82)$ \\
\hline \multicolumn{3}{|l|}{ Diabetes } \\
\hline Not available & 0 & $1(1 \%)$ \\
\hline None $(0)$ & 72 (95\%) & $71(92 \%)$ \\
\hline Adult onset, diet (1) & $3(4 \%)$ & $4(5 \%)$ \\
\hline Adult onset, insulin (2) & $1(1 \%)$ & $1(1 \%)$ \\
\hline \multicolumn{3}{|l|}{ Tobacco use } \\
\hline Not available & $1(1 \%)$ & $1(1 \%)$ \\
\hline None or $>10$ y ago $(0)$ & $39(51 \%)$ & $28(36 \%)$ \\
\hline Not current, $<10$ y ago (1) & $13(17 \%)$ & $17(22 \%)$ \\
\hline Current, $<1$ pack/d (2) & $15(20 \%)$ & $28(36 \%)$ \\
\hline Current, $>1$ pack/d (3) & $8(11 \%)$ & $3(4 \%)$ \\
\hline \multicolumn{3}{|l|}{ Hyperlipidemia } \\
\hline Not available & $7(9 \%)$ & $3(4 \%)$ \\
\hline Normal levels (0) & $37(49 \%)$ & $44(57 \%)$ \\
\hline Mild elevation, diet (1) & $7(9 \%)$ & $8(10 \%)$ \\
\hline Strict dietary control (2) & $1(1 \%)$ & $1(1 \%)$ \\
\hline Diet + drug control (3) & $24(32 \%)$ & $21(27 \%)$ \\
\hline \multicolumn{3}{|l|}{ Hypertension } \\
\hline Not available & 0 & $2(3 \%)$ \\
\hline None $(0)$ & $40(54 \%)$ & $35(45 \%)$ \\
\hline Single-drug therapy (1) & $23(30 \%)$ & $27(35 \%)$ \\
\hline 2-drug therapy (2) & $11(14 \%)$ & $11(14 \%)$ \\
\hline$>2$ drugs or uncontrolled (3) & $2(3 \%)$ & $2(3 \%)$ \\
\hline \multicolumn{3}{|l|}{ Carotid disease } \\
\hline Not available & 0 & $1(1 \%)$ \\
\hline No symptoms (0) & $67(88 \%)$ & $67(87 \%)$ \\
\hline Asymptomatic, but disease (1) & $4(53 \%)$ & $1(1 \%)$ \\
\hline TIA or temporary stroke (2) & $3(39 \%)$ & $5(6 \%)$ \\
\hline Stroke/neurological deficit (3) & $2(3 \%)$ & $3(4 \%)$ \\
\hline \multicolumn{3}{|l|}{ Cardiac status } \\
\hline Not available & 0 & $1(1 \%)$ \\
\hline Asymptomatic, normal ECG (0) & $39(51 \%)$ & $44(57 \%)$ \\
\hline Asymptomatic, remote or occult $\mathrm{MI}(1)$ & $33(43 \%)$ & $25(32 \%)$ \\
\hline Stable AP; drug-compensated CHF (2) & $4(5 \%)$ & $7(9 \%)$ \\
\hline \multicolumn{3}{|l|}{ Renal status } \\
\hline Not available & $1(1 \%)$ & $2(3 \%)$ \\
\hline No renal disease $(0)$ & $70(92 \%)$ & $69(90 \%)$ \\
\hline Creatinine $<210 \mu \mathrm{mol} / \mathrm{L}(1)$ & $5(7 \%)$ & $6(8 \%)$ \\
\hline \multicolumn{3}{|l|}{ Pulmonary status } \\
\hline Not available & 0 & $2(3 \%)$ \\
\hline Asymptomatic, $\mathrm{PFT}>80 \%$ of predicted $(0)$ & $64(84 \%)$ & $51(66 \%)$ \\
\hline Asymptomatic, PFT $65 \%$ to $80 \%$ of predicted (1) & $9(12 \%)$ & $21(27 \%)$ \\
\hline PFT $35 \%$ to $65 \%$ of predicted (2) & $3(4 \%)$ & $3(39 \%)$ \\
\hline Medication affecting sexual function & $49(64 \%)$ & $39(51 \%)$ \\
\hline Digoxin & $5(66 \%)$ & $3(4 \%)$ \\
\hline Diuretics & $12(16 \%)$ & $10(13 \%)$ \\
\hline Calcium-channel blockers & $16(21 \%)$ & $14(18 \%)$ \\
\hline Beta-blockers & $33(43 \%)$ & $26(34 \%)$ \\
\hline
\end{tabular}

TIA: transient ischemic attack, ECG: electrocardiogram, CHF: congestive heart failure, AP: angina pectoris, MI: myocardial infarction, PFT: pulmonary function test. 
TABLE 3

Proportion of Patients Reporting Sexual Dysfunction

\begin{tabular}{|c|c|c|c|c|c|c|c|c|c|c|c|c|}
\hline \multirow{2}{*}{$\begin{array}{c}\text { Sexual } \\
\text { Dysfunction } \\
\text { (aspect) }\end{array}$} & \multicolumn{2}{|c|}{ Pre, \% } & \multicolumn{2}{|c|}{$\begin{array}{c}3 \text { Weeks, } \\
\%\end{array}$} & \multicolumn{2}{|c|}{$\begin{array}{c}6 \text { Weeks, } \\
\%\end{array}$} & \multicolumn{2}{|c|}{$\begin{array}{c}13 \text { Weeks, } \\
\%\end{array}$} & \multicolumn{2}{|c|}{$\begin{array}{c}26 \text { Weeks, } \\
\% \\
\end{array}$} & \multicolumn{2}{|c|}{$\begin{array}{c}52 \text { Weeks, } \\
\%\end{array}$} \\
\hline & OR & EV & OR & EV & OR & EV & OR & EV & OR & EV & OR & EV \\
\hline Interest & 48 & 53 & 67 & $77^{*}$ & 70 & 60 & 51 & 55 & 52 & 58 & 45 & 63 \\
\hline Pleasure & 56 & 55 & 72 & $84^{*}$ & 74 & 65 & 62 & 59 & 58 & 71 & 51 & 70 \\
\hline Engagement & 55 & 60 & 76 & 77 & $77^{*}$ & 58 & 61 & 53 & 66 & 63 & 53 & 64 \\
\hline Orgasm & 53 & 57 & 72 & 78 & $77^{*}$ & 55 & 60 & 52 & 65 & 59 & 61 & 54 \\
\hline Erection & 54 & 57 & 73 & $74^{*}$ & 72 & 58 & 58 & 56 & 60 & 57 & 60 & 54 \\
\hline Any aspect & 66 & 74 & 79 & 82 & 77 & 68 & 69 & 70 & 76 & 71 & 66 & 69 \\
\hline
\end{tabular}

* Significantly different from Pre at $p<0.05$.

\section{A Open Repair}

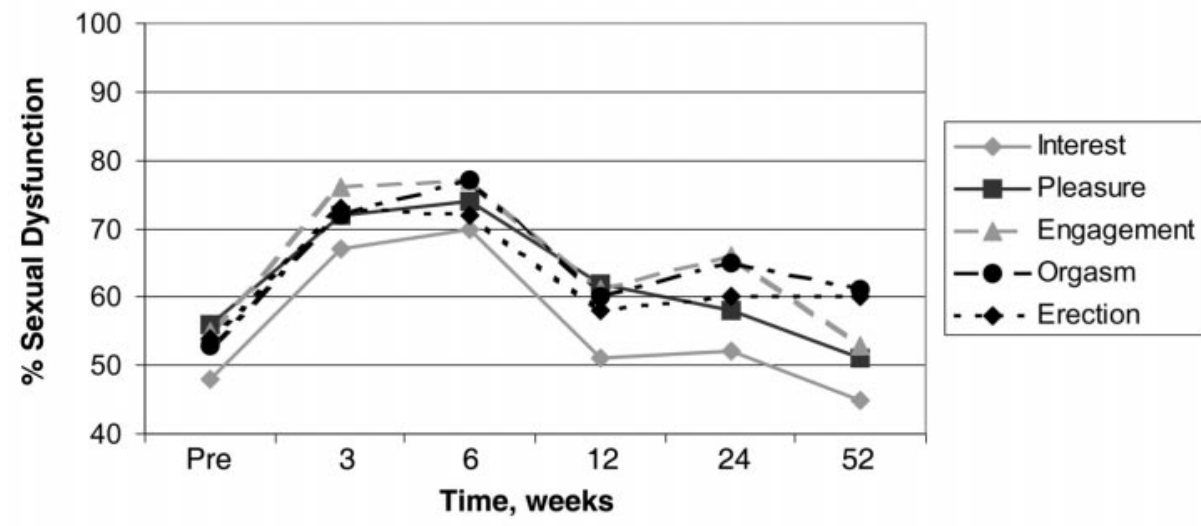

B

\section{EVAR}

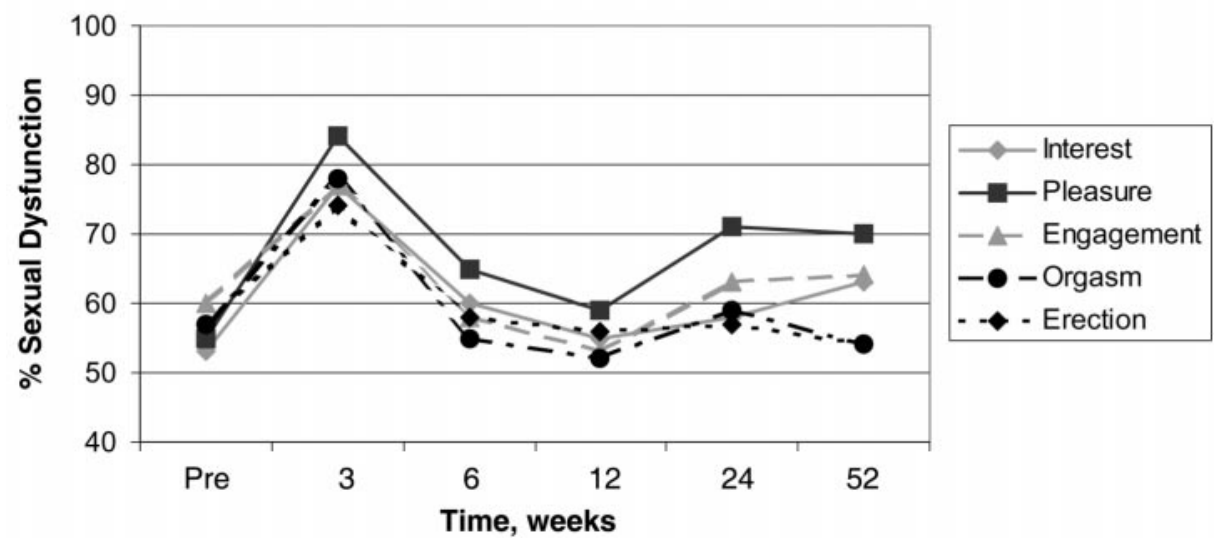

Figure $\triangleleft$ Proportion of sexual dysfunction for 5 aspects over time in the open $(\mathbf{A})$ and the EVAR (B) groups. 


\begin{tabular}{|c|c|c|c|c|c|c|c|c|c|c|}
\hline \multirow{3}{*}{$\begin{array}{l}\text { Sexual } \\
\text { Dysfunction } \\
\text { (aspect) }\end{array}$} & \multicolumn{10}{|c|}{$\begin{array}{l}\text { TABLE } 4 \\
\text { orting an Increase in Sexual Dysfunction } \\
\text { the Preoperative Situation }\end{array}$} \\
\hline & \multicolumn{2}{|c|}{$\begin{array}{c}3 \text { Weeks, } \\
\%\end{array}$} & \multicolumn{2}{|c|}{$\begin{array}{c}6 \text { Weeks, } \\
\%\end{array}$} & \multicolumn{2}{|c|}{$\begin{array}{c}13 \text { Weeks, } \\
\%\end{array}$} & \multicolumn{2}{|c|}{$\begin{array}{c}26 \text { Weeks, } \\
\%\end{array}$} & \multicolumn{2}{|c|}{$\begin{array}{c}52 \text { Weeks, } \\
\%\end{array}$} \\
\hline & OR & EV & OR & EV & OR & EV & OR & EV & OR & EV \\
\hline Interest & $45^{*}$ & 44 & 35 & 20 & 19 & 26 & 12 & 24 & 17 & 35 \\
\hline Pleasure & $41 \dagger$ & 42 & $33^{*}$ & 29 & 25 & 22 & 18 & 26 & 23 & 24 \\
\hline Engagement & $47 \dagger$ & 38 & $40^{*}$ & 17 & 24 & 22 & 24 & 26 & 24 & 38 \\
\hline Orgasm & $37^{*}$ & 33 & $35 \ddagger$ & 16 & 24 & 13 & 21 & 14 & 26 & 27 \\
\hline Erection & $31 *$ & $53^{*}$ & 22 & 18 & 17 & 19 & 20 & 20 & 22 & 26 \\
\hline
\end{tabular}

* Significantly different from Pre at $p<0.05$.

† Significantly different from Pre at $p<0.01$.

‡ Significantly different from Pre at $p<0.005$.

Although surgery did not result in a significant difference in the proportion of patients reporting sexual dysfunction between the 2 groups, the impact of surgery on sexual function in the OR group was greater than in the EVAR group. This effect could be demonstrated despite a higher number of internal iliac arteries being lost or sacrificed in the EVAR group, which underscores the multifactorial pathogenesis of sexual dysfunction after surgery.

The preoperative rate of sexual dysfunction on any aspect was $\sim 70 \%$ in our study, which may appear high compared to other reports, ${ }^{3,4}$ but there are several possible explanations for this difference. First, we had a better rate of response to our questionnaire than some other investigators have reported. $3,4,10$ The prospective study design and the willingness of participants to enroll in a randomized trial were factors in favor of compliance. In a retrospective setting, patients who already have sexual dysfunction are probably less likely to respond to a questionnaire assessing sexual functioning. This bias leads to an underestimation of the percentage of patients having sexual dysfunction.

Another explanation for the high sexual dysfunction rate in our study could be that the questionnaires were sent after randomization. The knowledge of having a potentially lifethreatening disease and awaiting an operation may have had an impact on quality of life and sexual functioning. Furthermore, the incidence of sexual dysfunction increases with age and the presence of comorbidities. ${ }^{11-13}$ Vascular disease, smoking, ischemic heart disease, hypertension, and diabetes are known to have an impact on sexual function. ${ }^{10,14,15}$

Xenos et al. ${ }^{3}$ and Lee et al. ${ }^{4}$ both performed retrospective studies by sending questionnaires to all AAA patients who underwent $O R$ and asked them to recall their sexual function preoperatively and 3 months postoperatively. As shown in other studies and also in ours, the impact of the operation on the quality of life has faded 3 months after the procedure. As such, this seems an acceptable time frame to assess sexual functioning. Furthermore, it does not seem likely that sexual function will change or improve after 3 months, as also shown in our data, so the reported postoperative sexual dysfunction rate at 3 months appears reliable. However, as Lee et al. ${ }^{4}$ also stated, the incidence of preoperative sexual dysfunction may be clouded by recall bias in retrospective studies. Many responders probably remember their sexual function to be better than it really was prior to the operation. Accordingly, the true prevalence of sexual dysfunction likely will be underestimated in these studies. Mulligan and Katz ${ }^{16}$ examined libido and erectile function in elderly men and found that only $15 \%$ had sexual intercourse, mostly due to erectile failure. Also, other studies reported sexual dysfunction rates in the same range as we found in our study. ${ }^{17,18}$

Xenos et al. ${ }^{3}$ compared erectile function after OR and EVAR in a retrospective study de- 
sign. They found significantly decreased sexual functioning after $O R$ and no deterioration after EVAR. In our study, no differences where found between OR and EVAR. A likely explanation for this may be that Xenos' study was not randomized. Despite the fact that baseline characteristics did not differ significantly between their groups, this retrospective study may have been flawed by bias.

A potential shortcoming of our study is that we did not record information about the opportunities for sexual activity, i.e., of having a spouse or a partner, which might have had an effect on the results. Another issue may be the medication taken by patients with AAA. Apart from the vascular disorder and other risk factors, some types of medication are known to possibly impair sexual function. ${ }^{19}$ However the relationship to a specific type of medication can be difficult to determine because existing comorbidities affect sexual function also.

Sexual functioning would appear to be an integral part of quality of life (QoL), which the DREAM trial also assessed.20 The preoperative QoL scores of the study group were lower on several domains of the Short Form-36 questionnaire but did not significantly differ from the scores of the age-matched general Dutch population. At the 3-week interval, both trial arms reported a significantly decreased OoL, but the OR group had significantly lower scores than the EVAR group. At 6 weeks, both groups showed a (partial) recovery of the QoL. Three months after surgery, both trial arms had regained their preoperative level. However, as the reported sexual dysfunction in this study is high, this might indicate that sexual activity in this population does not play an important role.

Another limitation in evaluating sexual dysfunction is that there are no validated questionnaires available on the issue. The Medical Outcomes Study evaluation we have used was selected as the most appropriate from several nonvalidated questionnaires. ${ }^{7}$ Better tools need to be developed to study sexual function after surgery.

Very few patients reported sexual dysfunction spontaneously at office visits. The high rate of preoperative sexual dysfunction makes it impossible for this study to analyze sexual dysfunction in patients who reported normal sexual function preoperatively. A much larger study would be needed to have enough power to detect differences between treatment groups. Taking into account that the preoperative rate of sexual dysfunction is $>65 \%$ in the target population and that randomized studies like these are increasingly hard to conduct, it is unlikely this type of evidence will ever be available. Nevertheless, reanalysis of the DREAM data will be performed after all the questionnaires are available up to the 24-month follow-up.

In conclusion, sexual dysfunction rates are high in this population, even at the outset. Endovascular and open elective AAA repair both have an impact on sexual functioning in the early postoperative period. After EVAR, recovery to preoperative levels is faster than after open repair, but at 3 months, sexual dysfunction levels are similar in both groups.

\section{APPENDIX}

Centers participating in the DREAM trial: The Netherlands: Catharina Hospital, Eindhoven: J. Buth, A.V. Tielbeek; University Hospital Groningen: E.L.G. Verhoeven, T. Prins; St. Elisabeth Hospital, Tilburg: J.F. Hamming, L.E.H. Lampmann; University Medical Center Maastricht: G.W.H. Schurink, M. de Haan; Academic Medical Center Amsterdam: R. Balm, J.A. Reekers; Maxima Medical Center, Veldhoven: M.H.M. Bender, H. Pasmans; University Medical Center Leiden: M.J.T. Visser, E. van der Linden; University Medical Center Utrecht: J.D. Blankensteijn, W.P.Th.M. Mali; Medical Center Rijnmond Zuid, Rotterdam: A.A.E.A. de Smet, D. Vroegindeweij; Rijnstate Hospital, Arnhem: S.M.M. van Sterkenburg, G.B. ten Haken; Martini Hospital, Groningen: J.H.B. Boomsma, H.R. van Dop; Medical Center Haaglanden, Westeinde, 's-Gravenhage: J.C.A. de Mol van Otterloo, T.P.W. de Rooij; Erasmus Medical Center, Rotterdam: M.R.H.M. van Sambeek, P. Pattynama; Leyenburg Hospital, 's-Gravenhage: C.M.A. Bruijninckx, H. van Overhagen; University Medical Center St. Radboud, Nijmegen: J.D. Blankensteijn, L. Schulze Kool; St. Franciscus Gasthuis, Rotterdam: A.C. van der Ham, 
J.J.I.M. van der Velden; Academic Medical Center VU, Amsterdam: W. Wisselink, F.C. van den Berg; Albert Schweitzer Hospital, Dordrecht: R.P. Tutein Nolthenius, T.R. Hendriksz; OLVG, Amsterdam: A.C. Vahl, C. de Vries; Meander Medical Center, Amersfoort: A.J.C. Mackaay; Bronovo Hospital, 's-Gravenhage: H.J. Smeets; Vlietland Hospital, Schiedam: L.M.C. van Dortmont; Deventer Hospital: B.H.P. Elsman; Hospital Bernhoven, Oss: T.M. Smits; Jeroen Bosch Hospital, 's-Hertogenbosch: R.M.M. van Loenhout, M.J. Rutten; Atrium Medical Center, Heerlen: J.A.W. Teijink, H.F. Odink; Oosterschelde Hospital, Goes: E.N. Yilmaz; Maxima Medical Center Eindhoven: G. den Butter.

Belgium: University Hospital Antwerpen: J. Poniewierski; University Medical Center Gent: F.E.G. Vermassen; St. Jozef Hospital, Turnhout: P. Stabel; St. Trudo Hospital, St. Truiden: F. van Elst.

\section{REFERENCES}

1. Dunn KM, Croft PR, Hackett GI. Association of sexual problems with social, psychological, and physical problems in men and women: a cross sectional population survey. J Epidemiol Community Health. 1999;53:144-148.

2. Morales A. Erectile dysfunction: an overview. Clin Geriatr Med. 2003;19:529-538.

3. Xenos ES, Stevens SL, Freeman MB, et al. Erectile function after open or endovascular abdominal aortic aneurysm repair. Ann Vasc Surg. 2003;17:530-538.

4. Lee ES, Kor DJ, Kuskowski MA, et al. Incidence of erectile dysfunction after open abdominal aortic aneurysm repair. Ann Vasc Surg. 2000; 14:13-19.

5. Sabri S, Cotton LT. Sexual function following aortoiliac reconstruction. Lancet. 1971;2:12181219.

6. Prinssen M, Buskens E, Blankensteijn JD. The Dutch Randomized Endovascular Aneurysm Management (DREAM) trial. Background, design and methods. J Cardiovasc Surg (Torino). 2002;43:379-384.
7. Brorsson B, Ifver J, Hays RD. The Swedish Health-Related Quality of Life Survey (SWEDQUAL). Qual Life Res. 1993;2:33-45.

8. Chaikof EL, Fillinger MF, Matsumura JS, et al. Identifying and grading factors that modify the outcome of endovascular aortic aneurysm repair. J Vasc Surg. 2002;35:1061-1066.

9. Dewar ML, Blundell PE, Lidstone D, et al. Effects of abdominal aneurysmectomy, aortoiliac bypass grafting and angioplasty on male sexual potency: a prospective study. Can J Surg. 1985;28:154-6,-159.

10. Wandell PE, Brorsson B. Assessing sexual functioning in patients with chronic disorders by using a generic health-related quality of life questionnaire. Qual Life Res. 2000;9:10811092.

11. Bacon CG, Mittleman MA, Kawachi I, et al. Sexual function in men older than 50 years of age: results from the health professionals follow-up study. Ann Intern Med. 2003;139:161-168.

12. Wespes E. Erectile dysfunction in the ageing man. Curr Opin Urol. 2000;10:625-628.

13. Montorsi F, Briganti A, Salonia A, et al. The ageing male and erectile dysfunction. BJU Int. 2003;92:516-520.

14. Hsueh WA. Sexual dysfunction with aging and systemic hypertension. Am J Cardiol. 1988;61: $18 \mathrm{H}-23 \mathrm{H}$.

15. Dey J, Shepherd MD. Evaluation and treatment of erectile dysfunction in men with diabetes mellitus. Mayo Clin Proc. 2002;77:276-282.

16. Mulligan T, Katz PG. Erectile failure in the aged: evaluation and treatment. J Am Geriatr Soc. 1988;36:54-62.

17. Kinsey AC, Pomeroy WR, Martin CE. Sexual behavior in the human male. 1948. Am J Public Health. 2003;93:894-898.

18. Feldman HA, Goldstein I, Hatzichristou DG, et al. Impotence and its medical and psychosocial correlates: results of the Massachusetts Male Aging Study. J Urol. 1994;151:54-61.

19. Thomas DR. Medications and sexual function. Clin Geriatr Med. 2003;19:553-562.

20. Prinssen $M$, Buskens $E$, Blankensteijn JD. on behalf of the DREAM trial participants. Quality of life after endovascular and open AAA repair. Results of a randomized trial. Eur J Vasc Endovasc Surg. 2004;27:121-127. 